\title{
Introduction to Special Issue
}

\author{
Leonard Bickman · Kimberly Eaton Hoagwood
}

Published online: 30 March 2010

(C) Springer Science+Business Media, LLC 2010

In September 2009 a conference was held at Vanderbilt University that formed the basis of this special issue. More details on the conference are provided in the next article by Taylor Haynes. The organizers and editors of this special issue took different paths in how they became involved in the conference. First we start with Bickman's involvement.

\section{Bickman's Perspective}

In 1999 I authored an essay in the American Psychologist entitled Practice Makes Perfect and Other Myths about Mental Health Services that expressed my concerns about the status of our field. In the ensuing decade we have made important advances in identifying effective treatments and in learning how to better implement community based evaluations. Despite this I believe that the effectiveness of mental health services for many of the children in America has not improved. This constitutes a crisis, albeit one that is not very obvious. I have drawn the following conclusions from the last decade that served as an impetus for the conference.

L. Bickman ( $\square)$

Center for Evaluation and Program Improvement, Nashville, TN, USA

e-mail: corinne.b.bickman@Vanderbilt.Edu

K. E. Hoagwood

Clinical Psychology in Psychiatry, Columbia University,

New York, NY, USA

K. E. Hoagwood

Research on Child and Adolescent Services for the New York

State Office of Mental Health, New York, NY, USA
- The way services are financed is a barrier to improving their effectiveness

- Most of the evidence based treatments that have been established as effective in research settings are difficult to implement in the real world and are not monitored to ensure their fidelity and effectiveness.

- There is little or no accountability for delivering effective services either by the funder or service provider

- Clients and their families do not know if the services they are receiving are effective and appear not to be aware that they don't know

- Current clinician training approaches are inadequate

- Little has been invested in research and evaluation in the real world

- Measurement of quality/effectiveness of mental health services is not routinely used in the real world

In examining our current condition it is tempting to move into a blame mode. The clinicians are resistant to change, agencies are avoiding accountability, governments are mired in their own bureaucracy and regulations, and the consumers haven't figured out they need to be demanding quality services not just more access. The researchers, well they are just happy publishing and winning grants. But the bottom line is what we are doing to make life better for children and their families who have mental health problems? I expressed these concerns in an editorial in this journal. The response was supportive but mostly apathetic. Yes, I have identified some of the major problems but what can we do about it? That was the impetus for me to initiate a conference and this special issue. The purpose was to bring together some of the best thinkers from different stakeholder groups who would move beyond seeking who to blame but who could more clearly define the problems and identify potential solutions. 
Realizing that this was going to be a major undertaking I asked Kim Hoagwood and Alan Kazdin to help organize an invitational conference. Alan, being president of APA, was only able to help on the initial planning but he provided some good advice. In November and December of 2008 we invited individuals to the meeting. We did not seek outside funding to support this effort so potential participants were told they would need to be able to pay their own way. In addition, before they came to the conference they would have to write a paper with a group of other invitees and commit to rapidly refining the paper for this special issue. Moreover, they had to agree to follow-up on an action agenda that would be produced during the conference. Clearly this was a challenging set of requirements.

\section{Hoagwood's Perspective}

I was drawn to this set of activities circuitously, as usual. One impetus came from discussions in 2008 with a few colleagues (Marc Atkins, Barbara Burns, Peter Jensen, Kelly Kelleher, Mary McKay, Len) about two imminent anniversaries that would occur in 2009. One was the 10th anniversary of the publication of the Surgeon General's Mental Health Report. The second was the 25th anniversary of the publication of Jane Knitzer's Unclaimed Children. In thinking about these sentinel events, I wondered what had been the key drivers for reform over the past one to two decades. Five stood out: (a) The Systems of Care Monograph and federal funding for the CMHS Children's Community-based Service Program; (b) the tripling of funding for research at NIMH in children's mental health from 1991 to 2001 which helped launch the Fort Bragg study, the ill-fated UNOCCAP, and a set of significant multi-site randomized clinical trials (e.g., MTA, TADS, TORDIA, RUPPS), among others; (c) The series of Surgeon General's Reports and the Children's Action Plan all published between 1999-2002 followed by the President's New Freedom Commission Report (SAMHSA 2003), each highlighting many of the same problems; (d) the public health-inspired IOM reports on the quality chasm in healthcare; and (e) the promotion of EBP dissemination to improve real world practice [e.g., NIMH's focus on effectiveness and dissemination/implementation science; SAMHSA's Science to Service agenda and National Registry of Effective Practices); professional association publications (APA's 1998 and 2008 reviews, plus three Task Force reports); other federal agencies or organizations (i.e., What Works Clearinghouse, Blueprints etc.); and counties, states, and the international psychiatric community initiatives (World Psychiatric Association; National Research Institute/National Association of State Mental Health Program Directors)]. These drivers had been fueled by a shared and explicit set of principles, consolidated support among important constituents, a set of research or practice priorities, and funding to back them up.

So what had been accomplished as a result of these quite astonishingly consistent initiatives? First, there was no doubt in my mind that significant scientific progress had been made in several important areas and that many children and families were better off now than they would have been one or two decades ago. The science and practice communities had made noticeable advances in, for instance, diagnosis-specific measurement and treatment, prevention and early identification, education and support for families.

But it seemed to me that there was an intractable fault line. Similar advances in the system of delivery-in the conveyance infrastructure for getting better services (or for that matter any services) out into communities and to families_-was foundationally flawed. The mechanisms, structure, organization and fiscal accountability of the public mental health system was antiquated and out of step with the changes in the broader world of healthcare. Healthcare reform was being driven by technology-supported quality improvement. I saw none of that happening within the public mental health system. It was a system in disrepair.

I also was concerned that our scientific studies on system change were often confined within predetermined (and predictable) disciplinary boundaries that severely constrained the circulation of ideas. We were operating in a theoretical vacuum.

So I was left wondering-where have these positive forces for change really left us? I was reminded of Paul Meehl's (1976) Six Phases of Disintegration: (a) Initial enthusiasm; (b) application to different situations; (c) initial disillusionment; (d) growing bafflement as inconsistent findings emerge; (e) ad hoc excuses; and (f) abandonment.

So when Len sent me his editorial and asked what I thought, I was ready to jump into action. I had been reading Pasteur's Quadrant (a book first mentioned to me by Marc Atkins). In it Stokes, a former professor of politics and public affairs, points out how the linear paradigm that dichotomizes basic "pure" science from applied "useful" science had held sway in the post World War II era and had been a prime instigator of government funding for academic research. Yet that paradigm flies in the face of actual scientific experience. Creative breakthroughs (such as Pasteur's studies leading to his germ theory of disease) combined progressively more nuanced exploratory and basic research with wider and broader potential applicability. Basic science questions combined with a broader scope of problems (i.e., public health framework) might lead to the kinds of breakthroughs that would hit at the intractable system problems. Currently applied and 
practical studies of services are largely devoid of theory or interest in basic science processes. So it was in the hope of busting through outdated paradigms and finding fresh air that I agreed to work on the conference and special issue of this journal. I wasn't disappointed.

\section{Organization of this Special Issue}

The papers in this two volume special issue reflect the best thinking on how to effect change. They include papers focused on specific service sectors (e.g., child welfare, schools); on workforce development; on organizational changes to structure system improvement; on attitudinal obstacles such as stigma; on culture and context.

Following this introduction is a paper that describes the conference and the main issues that were discussed. We also decided that it would be fitting to debrief as many as of the participants as possible. Several staff at Vanderbilt agreed to conduct semi-structured interviews with as many participants as they could before they left Nashville. The second section contains papers that were drafted before the meeting by groups of individuals as well as papers authored or co-authored by conference participants that emerged during and after the conference. All participants were invited to submit manuscripts. All manuscripts were peer reviewed. The next section describes the four action agendas that were developed during the conference. Members of each group agreed to be personally responsible for moving that agenda forward. Future issues of this journal will provide updates on their progress. In the last section we asked several individuals from foundations, government agencies, service provider organizations as well as researchers to comment on the draft manuscripts and the action agendas.

We did not seek external funding for this conference because that would have added a year to our planning, a year that we did not think we could afford. But the most important reason is accountability, a theme that was discussed several times at the meeting. Not having a sponsor meant that the participants were only accountable to themselves and each other. The point was to leave the meeting knowing that there is not someone else or some institution that will be responsible for what follows. As President Obama recently said: "Change will not come if we wait for some other person or some other time. We are the ones we've been waiting for. We are the change that we seek."

\section{Thank You}

We would like to thank those who made the conference possible. Peggy Westlake has been the organizing force assisted by Pat Abelson. Katherine Taylor Haynes our lead qualitative researcher at the center organized our efforts to interview participants. She was assisted by a small group: Susie Kelley, Emily Sheffer, Melanie Leslie, Lisa Demoret, and Michele Athay. We would like to thank the Dean of Peabody College for sponsoring the reception and Columbia University for its support. The Anne E. Casey Foundation provided funds to print additional copies of the special issue and to support an additional small planning meeting as a follow-up to this special issue. This journal will publish letters to the editor. If you have any comments on what you read please let us know. 